\title{
Adolescent substance use behavior and suicidal behavior for boys and girls: a cross- sectional study by latent analysis approach
}

\author{
Peng-Wei Wang ${ }^{1,2}$ and Cheng-Fang Yen ${ }^{1,2^{*}}$
}

\begin{abstract}
Background: Adolescent suicidal behavior may consist of different symptoms, including suicidal ideation, suicidal planning and suicidal attempts. Adolescent substance use behavior may contribute to adolescent suicidal behavior. However, research on the relationships between specific substance use and individual suicidal behavior is insufficient, as adolescents may not use only one substance or develop only one facet of suicidal behavior. Latent variables permit us to describe the relationships between clusters of related behaviors more accurately than studying the relationships between specific behaviors. Thus, the aim of this study was to explore how adolescent substance use behavior contributes to suicidal behavior using latent variables representing adolescent suicidal and substance use behaviors.
\end{abstract}

Method: A total of 13,985 adolescents were recruited using a stratified random sampling strategy. The participants indicated whether they had experienced suicidal ideation, planning and attempts and reported their cigarette, alcohol, ketamine and MDMA use during the past year. Latent analysis was used to examine the relationship between substance use and suicidal behavior.

Results: Adolescents who used any one of the above substances exhibited more suicidal behavior. The results of latent variables analysis revealed that adolescent substance use contributed to suicidal behavior and that boys exhibited more severe substance use behavior than girls. However, there was no gender difference in the association between substance use and suicidal behavior.

Conclusion: Substance use behavior in adolescents is related to more suicidal behavior. In addition, the contribution of substance use to suicidal behavior does not differ between genders.

\section{Background}

Suicidal behavior is a broad term consisting of a broad scope of thoughts and actions, with at least an intent to result in death, ranging from ideation to active, selfinflicted death [1]. Previous studies have indicated that suicidal ideation is associated with suicidal planning and attempts and that suicidal planning contributes to the occurrence of suicide attempts [2,3]. It is particularly difficult to differentiate suicidal ideation from suicidal attempts among adolescents [4]. Furthermore, studies have also demonstrated that suicidal ideation, planning

\footnotetext{
*Correspondence: chfaye@cc.kmu.edu.tw

'Department of Psychiatry, Kaohsiung Medical University Hospital, 100 Tzyou 1st Road, Kaohsiung 807, Taiwan

2Department of Psychiatry, Faculty of Medicine and Graduate Institute of Medicine, College of Medicine, Kaohsiung Medical University, Kaohsiung, Taiwan
}

(c) The Author(s). 2017 Open Access This article is distributed under the terms of the Creative Commons Attribution 4.0 International License (http://creativecommons.org/licenses/by/4.0/), which permits unrestricted use, distribution, and reproduction in any medium, provided you give appropriate credit to the original author(s) and the source, provide a link to the Creative Commons license, and indicate if changes were made. The Creative Commons Public Domain Dedication waiver (http://creativecommons.org/publicdomain/zero/1.0/) applies to the data made available in this article, unless otherwise stated.

and attempts may result from some candidate genes or imbalances in the interactions among genes [5, 6], indicating that suicidal ideation, planning and attempts are interrelated and that suicidal behavior can be viewed as a cluster of related phenomena which result from an unobserved force.

Adolescence is a critical period regarding the initial use of tobacco, alcohol and other substances [7], and the prevalence of adolescent substance use is high in many countries. In Australia, the rate of current tobacco use in adolescents is $10 \%$, and the rate of illicit drug during the past 12 months is 16\% [8]. In the United States, 14\% of grade 12 adolescents have used tobacco, and the lifetime prevalence of adolescent cannabis use is $23 \%$ [9]. A previous study in Taiwan reported that the overall prevalence of any substance use disorder is $11 \%$, with tobacco being the most common [10]. Research has 
found that the use of one type of substance may contribute to the use of another type of substance among adolescents [11, 12]. In addition, adolescents who use different types of substances may share similar genetic and environmental factors [13, 14]. Therefore, adolescent substance use can also be viewed as a class of observable behaviors which result from an unobserved force.

Adolescent substance use may result in many healthrelated problems, such as depression and abnormal brain functioning $[15,16]$. Substance use is also one of the risk factors that contribute to adolescent suicidal behavior [17]. Previous studies examining the relationship between substance use and suicidal behavior among adolescents have focused primarily on the types of substance use that increase the risk of suicidal behavior and on the degrees of association between the use of various types of substances and suicidal behavior [18, 19]. However, as described above, substance use can be considered a cluster of related behavioral phenomena. In addition, poly-substance use is common in adolescents [20], and research has demonstrated that combined use of multiple substances increases the risk of suicidal behavior [21]. Further research on the relationship between substance use and suicidal behavior in adolescents should examine multiple domains of substance and suicidal behavioral phenomena because both have a cluster of related behavioral phenomena. A latent variable can represent the unobserved force to result in several related observable behaviors. Latent variables analysis can examine the relationships between observable behavior and the unobserved force. Furthermore, latent analysis can describe the relationships among a class of events or observable phenomena that share similar characteristics rather than making concrete statements restricted to the relationships between more specific variables [22]. Therefore, latent variables analysis may be a good method by which to further our understanding of the relationship between substance use and suicidal behavior in adolescents.

Research has demonstrated that girls are more likely to experience suicidal ideation and attempts than boys [23] and that boys are more likely to use illicit substances, tobacco and alcohol than girls [24]. However, the gender influence on the relationship between substance use and suicidal behavior in adolescents is unclear. The present study used latent variable to represent two unobserved forces for suicidal and substance user behavior. Then we examined the relationship between two latent variables. The study aimed to examine the relationships between the use of four substances commonly used by adolescents (cigarettes, alcohol, ketamine, and 3,4-methylenedioxymethamphetamine [MDMA]) and three phenomena of suicidal behavior (suicidal ideation, planning and attempts) in adolescents. The present study also explored the gender difference in the contribution of adolescent substance use to suicidal behavior. The hypotheses were 1) adolescent substance use contributes to adolescent suicidal behavior in both boys and girls and 2) a gender difference exists in the strength of the contribution of adolescent substance use to suicidal behavior.

\section{Method \\ Participants}

The current study was based on data from the 2004 Project for the Health of Adolescents in Southern Taiwan, a research program studying the mental health status of adolescents living in four counties and three metropolitan areas in southern Taiwan. On the basis of the Taiwan-Fukien Demographic Fact Book [25], 10 senior high/vocational schools and 11 junior high schools were randomly selected from non-urban areas, and 19 senior high/vocational schools and 12 junior high schools were randomly selected from urban areas. The classes in the selected schools were stratified into three levels according to grade. A total of 17,130 were then randomly selected and 13,985 adolescents (81.64\%) completed all research questionnaires. The final sample size of each stratum was proportionate to the population size of the strata based on districts, schools and grades. The mean age of this group was 14.75 years (standard deviation [SD]: 1.77 years, range: $12-19$ years). The protocol was approved by the Institutional Review Board of Kaohsiung Medical University.

\section{Assessment}

\section{The questionnaire for experience in substance use (Q-ESU)}

The Q-ESU was used to assess each participant's experience of smoking, alcohol consumption, and illicit drug use (including ketamine and MDMA) during the preceding year because these were the most popular substances for adolescents [26]. In this study, the responses of the participants were dichotomously divided to represent whether the participants had smoked cigarettes at least once every week, consumed alcohol at least once every week, and had ever used ketamine and MDMA during the preceding year. The 2-week test-retest reliability of the items in the pilot study $(k)$ was $0.704-0.763(P<0.001)$. The $k$ coefficients of agreement between the information provided by the participants and reports from their parents regarding smoking, alcohol consumption, and illicit drug use ranged from 0.602 to $0.852(P<0.01)$.

\section{Suicidal ideation, planning, and attempts}

The 5-item questionnaire which were adapted from the epidemiological version of the Kiddie Schedule for Affective Disorders and Schizophrenia (K-SADS-E) [27] was used to assess the occurrence of three forms of suicidal ideation (items 1 to 3 ), suicidal planning (item 4) and suicide attempts (item 5) in the past year [28]. Each question elicited a "yes" or "no" answer. The Cohen's 
kappa coefficient of agreement $(\mathrm{\kappa})$ between the participants' self-reported suicide attempts and their parents' reports was $0.541(P<0.001)$ [28]. In this study, the participants who answered "yes" to any of the first three items were classified as having suicidal ideation, those who answered "yes" to the fourth item were classified as having made suicidal plans, and those who answered "yes" to the last item were classified as having attempted suicide.

\section{Procedure and statistical analysis}

Research assistants explained the purpose of the study to all students in the classes, emphasized respect for the students' privacy, and encouraged the students to participate. The adolescents were asked to anonymously complete the questionnaire based on the explanations of the research assistants and under the direction of the research assistants. Each student received a gift that was worth NT\$33 (one US dollar) at the end of the assessment.

The descriptive data analysis was performed using IBM SPSS Statistics 20. The prevalence rates of the use of each substance in the preceding year and the proportions of adolescents with different phenomena of suicidal behavior were examined. We compared the rates of substance use and suicidal behavior in boys and girls using the Chi-square test. The rates of suicidal behavior in substance users and non-substance users in both genders were also analyzed using the Chi-square test. A measurement invariance (MI) test enabled model comparison with latent variables [29]. We used MI to demonstrate identical constructs with the same structure across the genders in our model, in which substance use and suicidal behavior served as latent variables. After determining the measurement invariance, we compared the mean level of substance use and the strength of the contribution of substance use to suicidal behavior between boys and girls. For these analyses, multilevel structural equation modeling (SEM), which provided a framework for examining the measurement invariance and the differences in latent variables between groups, was performed using STATA 15 [30]. The multilevel SEM can adjust the clustering of students in classrooms and schools as well as analyze categorical data by using cluster robust maximum likelihood [31, 32]. The cluster robust maximum likelihood bases on Taylor series linearization approach for cluster and categorical data [33]. Although, our sample was proportionate to the population size of the strata based on districts, schools and grades, we used age as weighting adjustment during analysis to draw a more reliable result. The hypothesized model is presented in Fig. 1. The indices used to estimate the goodness of fit of the model were the comparative fit index $(\mathrm{CFI})>0.9$, and the root mean square error of approximation (RMSEA) $<0.1$. The index used to

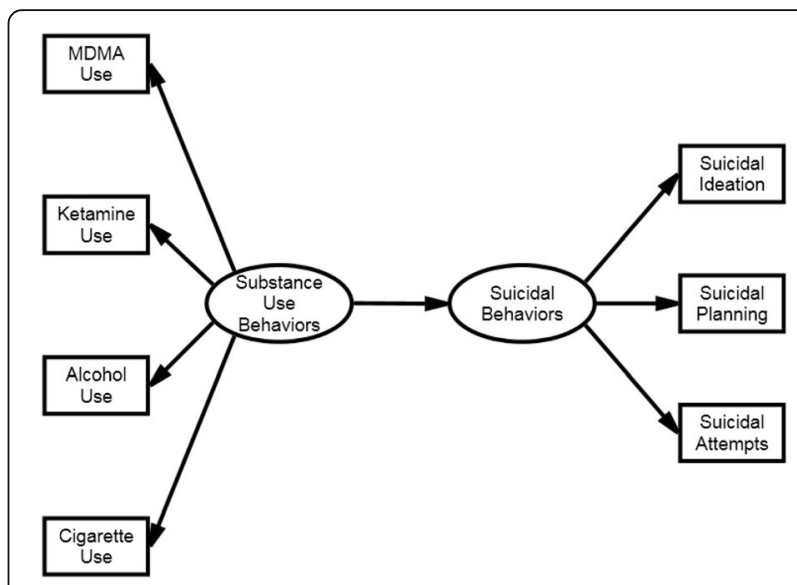

Fig. 1 Model of the relationship between adolescent substance use and suicidal behavior

estimate the goodness of fit of the model and measurement invariance was Standardized root mean squared residual (SRMR) [34, 35]. A two-tailed $P$ value of less than 0.05 was considered statistically significant.

\section{Results}

The rate of smoking once or more during the past month was $6.76 \%$ which was closed to our national tobacco survey [36]. The rate of alcohol use once or more during the past month was $17.41 \%$ which was closed to the previous result [37]. The rate of ketamine use during past year was also closed to results from a national survey study [26]. The results of the comparisons of substance use and suicidal behavior between girls and boys are displayed in Table 1. The results indicated that girls had lower rates of smoking and alcohol use than boys; however, no significant gender differences in the rates of MDMA and ketamine use were found. Girls had higher rates of suicidal ideation, planning and attempts than boys.

The results of the comparisons of suicidal ideation, planning and attempts between boys and girls with and without substance use are presented in Table 2. Regardless of the type of substance boys used, those with

Table 1 Comparisons of substance use and suicidal behavior between girls and boys

\begin{tabular}{lllll}
\hline & $\begin{array}{l}\text { Girls } \\
(n=7374) \\
n(\%)\end{array}$ & $\begin{array}{l}\text { Boys } \\
(n=6611) \\
n(\%)\end{array}$ & $x^{2}$ & $P$ \\
\hline Cigarette use & $121(1.64)$ & $311(4.70)$ & 109.27 & $<0.001$ \\
Alcohol use & $54(0.73)$ & $112(1.69)$ & 27.50 & $<0.001$ \\
MDMA use & $31(0.42)$ & $29(0.44)$ & 0.03 & 0.898 \\
Ketamine use & $28(0.38)$ & $23(0.35)$ & 0.10 & 0.779 \\
Suicidal ideation & $1431(19.41)$ & $800(12.10)$ & 138.74 & $<0.001$ \\
Suicidal planning & $921(12.49)$ & $622(9.41)$ & 33.76 & $<0.001$ \\
Suicidal attempts & $759(10.29)$ & $358(5.42)$ & 112.85 & $<0.001$ \\
\hline
\end{tabular}


Table 2 Rates of suicidal ideation, planning and attempts among boys and girls with and without substance use

\begin{tabular}{|c|c|c|c|c|c|c|}
\hline & $\begin{array}{l}\text { Suicidal ideation } \\
n(\%)\end{array}$ & $P$ value & $\begin{array}{l}\text { Suicidal plaining } \\
n(\%)\end{array}$ & $P$ value & $\begin{array}{l}\text { Suicidal attempts } \\
n(\%)\end{array}$ & $P$ value \\
\hline \multicolumn{7}{|l|}{ Boys } \\
\hline \multicolumn{7}{|l|}{ Cigarette use } \\
\hline $\operatorname{Yes}(n=311)$ & 64 (20.58) & $<0.001$ & 60 (19.29) & $<0.001$ & 39 (12.54) & $<0.001$ \\
\hline $\mathrm{No}(n=6300)$ & 736 (11.68) & & $562(8.92)$ & & $319(5.06)$ & \\
\hline \multicolumn{7}{|l|}{ Alcohol use } \\
\hline Yes $(n=112)$ & $30(26.79)$ & $<0.001$ & $25(22.32)$ & $<0.001$ & 19 (16.96) & $<0.001$ \\
\hline No $(n=6499)$ & 770 (11.85) & & 597 (9.19) & & $339(5.22)$ & \\
\hline \multicolumn{7}{|l|}{ Ketamine use } \\
\hline Yes $(n=23)$ & $10(38.46)$ & 0.001 & 8 (34.78) & 0.002 & $5(21.74)$ & 0.012 \\
\hline No $(n=6588)$ & $790(12.00)$ & & $614(9.32)$ & & $353(5.36)$ & \\
\hline \multicolumn{7}{|l|}{ MDMA use } \\
\hline Yes $(n=29)$ & $16(44.44)$ & $<0.001$ & $12(33.33)$ & $<0.001$ & $9(25.00)$ & $<0.001$ \\
\hline No $(n=6582)$ & 784 (11.92) & & $610(9.28)$ & & $349(5.31)$ & \\
\hline \multicolumn{7}{|l|}{ Girls } \\
\hline \multicolumn{7}{|l|}{ Cigarette use } \\
\hline $\operatorname{Yes}(n=121)$ & $63(52.06)$ & $<0.001$ & $49(40.50)$ & $<0.001$ & 47 (38.84) & $<0.001$ \\
\hline $\mathrm{No}(n=7253)$ & $1378(18.90)$ & & 872 (12.05) & & $712(9.82)$ & \\
\hline \multicolumn{7}{|l|}{ Alcohol use } \\
\hline Yes $(n=54)$ & $26(48.15)$ & $<0.001$ & $23(42.59)$ & $<0.001$ & $23(42.59)$ & $<0.001$ \\
\hline No $(n=7320)$ & 1405 (19.19) & & $898(12.27)$ & & 736 (10.05) & \\
\hline \multicolumn{7}{|l|}{ Ketamine use } \\
\hline Yes $(n=28)$ & $13(46.43)$ & $<0.001$ & $10(33.33)$ & 0.003 & $9(47.37)$ & 0.002 \\
\hline No $(n=7346)$ & $1418(19.30)$ & & $913(12.43)$ & & $750(10.21)$ & \\
\hline \multicolumn{7}{|l|}{ MDMA use } \\
\hline Yes $(n=31)$ & $12(34.48)$ & 0.027 & $10(28.57)$ & 0.009 & $9(25.71)$ & 0.007 \\
\hline No $(n=7343)$ & 1419 (19.34) & & $911(12.41)$ & & $750(10.21)$ & \\
\hline
\end{tabular}

substance use had higher rates of suicidal ideation, planning, and attempts than those without substance use. In addition, girls with any substance use had higher rates of suicidal ideation, planning, and attempts than girls without substance use.

The results of the comparisons of suicidal ideation, planning and attempts between boys and girls with substance use are displayed in Table 3. Girls with smoking and alcohol use had higher rates of all types of suicidal behavior than boys with smoking and alcohol use. However, there was no gender difference in any type of suicidal behavior among adolescents with ketamine or MDMA use.

The SRMR for the unconstrained model、 equal factor loading model and equal factor loading factor and intercept model are 0.0093, 0.0093 and 0.0096, respectively. The fit indices for measurement invariance were acceptable (Table 4). This indicated that the model fulfilled measurement invariance and was valid for boys and girls.

Table 3 Comparisons of suicidal ideation, planning and attempts between girls and boys with substance use

\begin{tabular}{|c|c|c|c|c|c|c|c|c|c|c|c|c|}
\hline & \multicolumn{3}{|c|}{ Cigarette use } & \multicolumn{3}{|c|}{ Alcohol use } & \multicolumn{3}{|c|}{ Ketamine use } & \multicolumn{3}{|l|}{ MDMA use } \\
\hline & $\begin{array}{l}\text { Girls } \\
(n=121) \\
n(\%)\end{array}$ & $\begin{array}{l}\text { Boys } \\
(n=311) \\
n(\%)\end{array}$ & $P$ value & $\begin{array}{l}\text { Girls } \\
(n=54) \\
n(\%)\end{array}$ & $\begin{array}{l}\text { Boys } \\
(n=112) \\
n(\%)\end{array}$ & $P$ value & $\begin{array}{l}\text { Girls } \\
(n=28) \\
n(\%)\end{array}$ & $\begin{array}{l}\text { Boys } \\
(n=23) \\
n(\%)\end{array}$ & $P$ value & $\begin{array}{l}\text { Girls } \\
(n=31) \\
n(\%)\end{array}$ & $\begin{array}{l}\text { Boys } \\
(n=29) \\
n(\%)\end{array}$ & $P$ value \\
\hline Suicidal ideation & $63(52.06)$ & $64(20.58)$ & $<0.001$ & $26(48.15)$ & $30(26.79)$ & 0.006 & $13(46.43)$ & $10(38.46)$ & 0.712 & $12(34.29)$ & $16(44.44)$ & 0.264 \\
\hline Suicidal planning & $49(40.50)$ & $60(19.29)$ & $<0.001$ & $23(42.59)$ & $25(22.32)$ & 0.007 & $10(33.33)$ & $8(34.78)$ & 0.838 & $10(28.57)$ & $12(33.33)$ & 0.664 \\
\hline Suicidal attempts & $47(38.84)$ & 39 (12.54) & $<0.001$ & $23(42.59)$ & $19(16.96)$ & $<0.001$ & $9(47.37)$ & $5(21.74)$ & 0.353 & 9 (25.71) & $9(25.00)$ & 0.945 \\
\hline
\end{tabular}


Table 4 Fitting indices for each model

\begin{tabular}{llll}
\hline & CFI & RMSEA & SRMR \\
\hline Unconstrained model & 0.997 & 0.010 & 0.0093 \\
Equal factor loading model & 0.997 & 0.011 & 0.0093 \\
Equal factor loading and intercept model & 0.995 & 0.013 & 0.0096 \\
\hline
\end{tabular}

Substance use contributed to suicidal behavior in both girls and boys (girls' structural coefficient: 0.34, $P<0.001$; boys' structural coefficient: $0.53, P<0.001$; girls' standardized structural coefficient: 0.18 ; boys' standardized structural coefficient: 0.24). However, there was no gender difference in the relationship between substance use behavior and suicidal behavior (Chi-square for differences between parameters: $1.069, P>0.05)$. In addition, the level of substance use behavior differed significantly between genders (girls' mean: 0.015; boys' mean: $0.041 ; P<0.001$ ) (Table 5).

\section{Discussion}

The first major finding of the present study, according to the latent variables analysis, was that substance use behavior positively contributes to suicidal behavior in both girls and boys. Substance use may lead to failure in developmental tasks, such as healthy interaction with peers, and in daily obligations, such as attending school or completing school work [38], which may further increase the risk of suicidal behavior. Meanwhile, acute drug intoxication may impair users' judgment, reduce their inhibition, and decrease their impulsive control, all of which increase the likelihood of suicidal behavior [39]. Chronic substance use may also have a negative impact on adolescent brain development $[16,40]$. In addition, adolescents who engage in chronic substance use often exhibit changes in behavioral, affective, and cognitive processes characterized as underdeveloped regulation of aggression and impulsivity [41]. Thus, substance use may contribute to suicidal behavior via multiple pathways.

The present study found that although there were gender differences in substance use and suicidal behavior, the contribution of adolescent substance use to suicidal behavior did not differ between genders. This result was consistent with the results of a previous study that reported that adolescent alcohol use is linked to suicidal behavior, although this association did not differ between boys and girls [42]. Therefore, both results suggest the existence of a gender-independent mechanism underlying the link between substance use behavior and suicidal behavior in adolescents. Further study is needed to explore this mechanism.

The present study found that the rates of all types of suicidal behavior were higher in girls than in boys. A previous study in the US also reported that adolescent girls had higher rates of suicidal ideation, planning and attempts than adolescent boys [43]. The present study found that girls had lower rates of smoking and alcohol use than boys but observed no significant gender differences in the rates of MDMA and ketamine use. However, the results of latent group comparisons in the present study indicated that boys had higher levels of

Table 5 Factor loadings, structural coefficient and standardized loading for the structural equation model

\begin{tabular}{|c|c|c|c|c|}
\hline \multicolumn{3}{|l|}{ Boys } & \multicolumn{2}{|l|}{ Girls } \\
\hline $\begin{array}{l}\text { Factor loadings }{ }^{\mathrm{a}} / \\
\text { structure coefficient }^{\mathrm{b}}\end{array}$ & $\begin{array}{l}\text { Standardized } \\
\text { Factor loadings }{ }^{\mathrm{a}} / \\
\text { structure coefficient }^{\mathrm{b}}\end{array}$ & $p$ & $\begin{array}{l}\text { Factor loadings }{ }^{\mathrm{a}} / \\
\text { structure coefficient }^{\mathrm{b}}\end{array}$ & $\begin{array}{l}\text { Standardized } \\
\text { Factor } \\
\text { loadings }^{\mathrm{a} /} \\
\text { structure } \\
\text { coefficient }^{\mathrm{b}}\end{array}$ \\
\hline
\end{tabular}

\begin{tabular}{|c|c|c|c|c|c|c|c|c|}
\hline $\begin{array}{l}\text { Substance use } \\
\text { behavior }\end{array}$ & $\rightarrow$ & $\begin{array}{l}\text { Suicidal } \\
\text { behavior }\end{array}$ & 0.53 & 0.24 & 0.013 & 0.34 & 0.18 & $<0.001$ \\
\hline $\begin{array}{l}\text { Substance use } \\
\text { behavior }\end{array}$ & $\rightarrow$ & $\begin{array}{l}\text { Cigarette } \\
\text { use }\end{array}$ & 1 & 0.44 & & 1 & 0.91 & \\
\hline $\begin{array}{l}\text { Substance use } \\
\text { behavior }\end{array}$ & $\rightarrow$ & $\begin{array}{l}\text { Alcohol } \\
\text { use }\end{array}$ & 0.55 & 0.40 & $<0.001$ & 0.35 & 0.51 & 0.018 \\
\hline $\begin{array}{l}\text { Substance use } \\
\text { behavior }\end{array}$ & $\rightarrow$ & MDMA use & 0.24 & 0.35 & 0.008 & 0.17 & 0.28 & $<0.001$ \\
\hline $\begin{array}{l}\text { Substance use } \\
\text { behavior }\end{array}$ & $\rightarrow$ & $\begin{array}{l}\text { Ketamine } \\
\text { use }\end{array}$ & 0.24 & 0.31 & 0.015 & 0.18 & 0.31 & $<0.001$ \\
\hline $\begin{array}{l}\text { Suicidal } \\
\text { behavior }\end{array}$ & $\rightarrow$ & $\begin{array}{l}\text { Suicidal } \\
\text { idea }\end{array}$ & 1 & 0.64 & & 1 & 0.59 & \\
\hline $\begin{array}{l}\text { Suicidal } \\
\text { behavior }\end{array}$ & $\rightarrow$ & $\begin{array}{l}\text { Suicidal } \\
\text { planning }\end{array}$ & 0.95 & 0.67 & $<0.001$ & 0.91 & 0.64 & $<0.001$ \\
\hline $\begin{array}{l}\text { Suicidal } \\
\text { behavior }\end{array}$ & $\rightarrow$ & $\begin{array}{l}\text { Suicidal } \\
\text { attempts }\end{array}$ & 0.72 & 0.66 & $<0.001$ & 0.94 & 0.72 & $<0.001$ \\
\hline
\end{tabular}

${ }^{\mathrm{a}}$ coefficients for measurement model; ${ }^{\mathrm{b}}$ coefficient for structure model 
substance use than girls. This result, obtained by latent analysis, provides robust evidence of a gender difference in adolescent substance use because adolescents typically use more than one type of drug [24]. Several factors may be responsible for the gender difference in adolescent substance use behavior. First, adolescent females have lower impulsivity, sensation-seeking and disinhibition than adolescent boys [44]. Second, attention deficient hyperactivity disorder, which may be linked to substance use, is more common in boys than in girls [45]. Third, environmental factors, such as cultural effects, which include cultural variations in sensation-seeking and impulse control, and peer effects, which include attracting friends/acceptance and contacting deviant peers, may also be responsible for the gender difference in substance use [44, 46, 47].

There were several limitations of this study. First, the data were provided by the adolescent subjects; thus, the possible issue of shared-method variance resulting from the sole data source requires careful consideration. Second, depression was not taken into consideration in our study. Depression is a risk factor for suicidal behavior and a common comorbidity for adolescents with substance uses [48]. Third, only adolescents who attended school were enrolled in this research. Fourth, the dichotomous response and lower prevalence rates for selected substance as well as not including other substance such as marmarijuana, cocaine, opioids, may limit the generalization of the findings. Fifth, the causal relationship cannot be determined because of the crosssectional nature of the study. The relationships between adolescents' substance use and their suicidal behavior could be influenced by several factors: young people may consider suicide because of substance use, they may use substances to cope with suicidal crises or both substance abuse and suicidal behavior may be the result of various confounders. Further study is therefore needed to determine precise causality, as other relationships may also exist that influence the relationship between substance and suicidal behavior. Despite these limitations, the present study increases our understanding of gender issues on adolescent substance use, as adolescent substance use can manifest as different behavioral phenomena. In addition, the contribution of adolescent substance use to suicidal behavior was found to be gender-independent. This finding suggests that mental health professionals should pay similar attention to substance use in girls and boys when developing and implementing prevention and intervention strategies for suicidal behavior in adolescents.

\section{Abbreviations}

CFI: Comparative fit index; K-SADS-E: Kiddie schedule for affective disorders and schizophrenia; MDMA: 3,4-methylenedioxymethamphetamine; MI: Measurement invariance; Q-ESU: The questionnaire for experience in substance use; RMSEA: Root mean square error of approximation SEM: Structural equation modeling

\section{Acknowledgements \\ None.}

\section{Funding}

This study was founded by Kaohsiung Medical University Hospital (grant number KMUH105-5 T04 and KMUH104-4 T05). The KMUH105-5 T04 supported the study analysis and KMUH104-4 T05 supported the interpretation of data and English editing.

\section{Availability of data and materials}

The datasets used and/or analyzed during the current study are available from the corresponding author on request.

\section{Authors' contributions}

PWW was involved in drafting and revising the manuscript. CFY was involved in the analysis and interpretation of the data. Both authors read and approved the final manuscript.

\section{Ethics approval and consent to participate}

The protocol was approved by the Institutional Review Board of Kaohsiung Medical University. Legal guardian to provide consent to participate in their stead because members of a study are not capable of providing ethical consent to participate for themselves.

\section{Consent for publication}

Not applicable.

\section{Competing interests}

The authors declare that they have no competing interests.

\section{Publisher's Note}

Springer Nature remains neutral with regard to jurisdictional claims in published maps and institutional affiliations.

Received: 17 March 2017 Accepted: 17 November 2017

Published online: 08 December 2017

\section{References}

1. Shlosberg D, Zalsman G, Shoval G. Emerging issues in the relationship between adolescent substance use and suicidal behavior. Isr J Psychiatry Relat Sci. 2014;51(4):262-7.

2. Tang J, Yu Y, Wu Y, Du Y, Ma Y, Zhu H, Zhang P, Liu Z. Association between non-suicidal self-injuries and suicide attempts in Chinese adolescents and college students: a cross-section study. PLoS One. 2011;6(4):e17977.

3. Kessler RC, Borges G, Walters EE. PRevalence of and risk factors for lifetime suicide attempts in the national comorbidity survey. Arch Gen Psychiatry. 1999;56(7):617-26.

4. Kosky R, Silburn S, Zubrick SR. Are children and adolescents who have suicidal thoughts different from those who attempt suicide? J Nerv Ment Dis. 1990;178(1):38-43.

5. Sokolowski M, Wasserman J, Wasserman D. An overview of the neurobiology of suicidal behaviors as one meta-system. Mol Psychiatry. 2015;20(1):56-71.

6. Sadkowski M, Dennis B, Clayden RC, Elsheikh W, Rangarajan S, Dejesus J, Samaan Z. The role of the serotonergic system in suicidal behavior. Neuropsychiatr Dis Treat. 2013;9:1699-716.

7. Chambers RA, Taylor JR, Potenza MN. Developmental neurocircuitry of motivation in adolescence: a critical period of addiction vulnerability. Am J Psychiatr. 2003;160(6):1041-52.

8. Australian Institute of Health and Welfare. Making progress : the health, development and wellbeing of Australia's children and young people. Canberra: Australian Institute of Health and Welfare; 2008.

9. Johnston LD, O'Malley PM, Bachman JG, Schulenberg JE. Monitoring the future National Survey Results on drug use, 1975-2014. Overview, key findings on adolescent drug use. Inst Soc Res. 2015;1-89.

10. Chong MY, Chan KW, Cheng AT. Substance use disorders among adolescents in Taiwan: prevalence, sociodemographic correlates and psychiatric co-morbidity. Psychol Med. 1999;29(6):1387-96. 
11. Vega WA, Gil AG. Revisiting drug progression: long-range effects of early tobacco use. Addiction. 2005;100(9):1358-69.

12. Patton GC, Coffey C, Carlin JB, Sawyer SM, Lynskey M. Reverse gateways? Frequent cannabis use as a predictor of tobacco initiation and nicotine dependence. Addiction. 2005;100(10):1518-25.

13. Van Ryzin MJ, Fosco GM, Dishion TJ. Family and peer predictors of substance use from early adolescence to early adulthood: an 11-year prospective analysis. Addict Behav. 2012;37(12):1314-24.

14. Kendler KS, Chen X, Dick D, Maes H, Gillespie N, Neale MC, Riley B. Recent advances in the genetic epidemiology and molecular genetics of substance use disorders. Nat Neurosci. 2012;15(2):181-9.

15. Bond L, Toumbourou JW, Thomas L, Catalano RF, Patton G. Individual, family, school, and community risk and protective factors for depressive symptoms in adolescents: a comparison of risk profiles for substance use and depressive symptoms. Prev Sci. 2005:6(2):73-88.

16. Squeglia LM, Jacobus J, Tapert SF. The influence of substance use on adolescent brain development. Clin EEG Neurosci. 2009:40(1):31-8.

17. Wolitzky-Taylor KB, Ruggiero KJ, McCart MR, Smith DW, Hanson RF, Resnick HS, de Arellano MA, Saunders BE, Kilpatrick DG. Has adolescent suicidality decreased in the United States? Data from two national samples of adolescents interviewed in 1995 and 2005. J Clin Child Adolesc Psychol. 2010;39(1):64-76.

18. Afifi TO, Cox BJ, Katz LY. The associations between health risk behaviours and suicidal ideation and attempts in a nationally representative sample of young adolescents. Can J Psychiatr. 2007;52(10):666-74.

19. Pompili $M$, Serafini $G$, Innamorati $M$, Biondi $M$, Siracusano A, Di Giannantonio M, Giupponi G, Amore M, Lester D, Girardi P, et al. Substance abuse and suicide risk among adolescents. Eur Arch Psychiatry Clin Neurosci. 2012;262(6):469-85.

20. Rodríguez-Arias M, Aguilar MA. Polydrug use in adolescence. London: INTECH Open Access Publisher; 2012.

21. Kokkevi A, Richardson C, Olszewski D, Matias J, Monshouwer K, Bjarnason T. Multiple substance use and self-reported suicide attempts by adolescents in 16 European countries. Eur Child Adolesc Psychiatry. 2012;21(8):443-50.

22. Bollen KA. Latent variables in psychology and the social sciences. Annu Rev Psychol. 2002:53(1):605-34.

23. Rhodes AE, Boyle MH, Bridge JA, Sinyor M, Links PS, Tonmyr L, Skinner R, Bethell JM, Carlisle C, Goodday S, et al. Antecedents and sex/gender differences in youth suicidal behavior. World J Psychiatry. 2014;4(4):120-32.

24. United States Department of $\mathrm{H}_{1}$ Human Services, Substance A, Mental Health Services Administration, Center for Behavioral Health S, Quality National Survey on drug use and health, 2013. In: Inter-university consortium for political and social research (ICPSR) [distributor]; 2014.

25. Ministry of the Interior (ed.): 2002. Taiwan-Fukien Demographic Fact Book. Taipei, Taiwan (in Chinese): Republic of China. Executive Yuan; 2002.

26. Chen WJ, Fu TC, Ting TT, Huang WL, Tang GM, Hsiao CK, Chen CY. Use of ecstasy and other psychoactive substances among school-attending adolescents in Taiwan: national surveys 2004-2006. BMC Public Health. 2009;9:27.

27. Puig-Antich J, Blau S, Marx N, Greenhill LL, Chambers W. Prepubertal major depressive disorder: a pilot study. J Am Acad Child Psychiatry. 1978:17(4):695-707.

28. Tang TC, Ko CH, Yen JY, Lin HC, Liu SC, Huang CF, Yen CF. Suicide and its association with individual, family, peer, and school factors in an adolescent population in southern Taiwan. Suicide Life Threat Behav. 2009;39(1):91-102.

29. Van de Schoot R, Lugtig P, Hox J. A checklist for testing measurement invariance. Eur J Dev Psychol. 2012;9(4):486-92.

30. Van De Schoot R, Schmidt P, De Beuckelaer A, Lek K, Zondervan-Zwijnenburg M. Editorial: Measurement Invariance. Front Psychol. 2015;6:1064.

31. Cameron AC, Miller DL. A practitioner's quide to cluster-robust inference. J Hum Resour. 2015;50(2):317-72.

32. Rhemtulla M, Brosseau-Liard PE, Savalei V. When can categorical variables be treated as continuous? A comparison of robust continuous and categorical SEM estimation methods under suboptimal conditions. Psychol Methods. 2012;17(3):354-73.

33. Williams RL. A note on robust variance estimation for cluster-correlated data. Biometrics. 2000;56(2):645-6.

34. Hortensius L: Project for introduction to multivariate statistics: measurement invariance. 2012.

35. Kline RB. Principles and practice of structural equation modeling. Fourth ed. 2016
36. Department of Health. Taiwanese Teenagers Smoking. Available online: http://tobacco.hpa.gov.tw/Show.aspx?Menuld=825. Accessed 2006.

37. Hung CC, Chiang YC, Chang HY, Yen LL. Path of socialization and cognitive factors' effects on adolescents' alcohol use in Taiwan. Addict Behav. 2011; 36(8):807-13.

38. Lewinsohn PM, Gotlib IH, Seeley JR. Adolescent psychopathology: IV. Specificity of psychosocial risk factors for depression and substance abuse in older adolescents. J Am Acad Child Adolesc Psychiatry. 1995;34(9):1221-9.

39. Mann JJ. Neurobiology of suicidal behaviour. Nat Rev Neurosci. 2003;4(10):819-28.

40. Volkow N, Li T-K. The neuroscience of addiction. Nat Neurosci. 2005;8(11):1429-30.

41. Clark DB, Cornelius JR, Kirisci L, Tarter RE. Childhood risk categories for adolescent substance involvement: a general liability typology. Drug Alcohol Depend. 2005;77(1):13-21.

42. Swahn MH, Bossarte RM. Gender, early alcohol use, and suicide ideation and attempts: findings from the 2005 youth risk behavior survey. J Adolesc Health. 2007;41(2):175-81.

43. Husky MM, Olfson M, He JP, Nock MK, Swanson SA, Merikangas KR. Twelvemonth suicidal symptoms and use of services among adolescents: results from the National Comorbidity Survey. Psychiatr Serv. 2012;63(10):989-96.

44. Shulman EP, Harden KP, Chein JM, Steinberg L. Sex differences in the developmental trajectories of impulse control and sensation-seeking from early adolescence to early adulthood. J Youth Adolesc. 2015:44(1):1-17.

45. Zulauf CA, Sprich SE, Safren SA, Wilens TE. The complicated relationship between attention deficit/hyperactivity disorder and substance use disorders. Curr Psychiatry Rep. 2014;16(3):436.

46. Okoli C, Greaves L, Fagyas V. Sex differences in smoking initiation among children and adolescents. Public Health. 2013;127(1):3-10.

47. Kirisci L, Mezzich AC, Reynolds M, Tarter RE, Aytaclar S. Prospective study of the association between neurobehavior disinhibition and peer environment on illegal drug use in boys and girls. Am J Drug Alcohol Abuse. 2009:35(3):145-50

48. Galaif ER, Sussman S, Newcomb MD, Locke TF. Suicidality, depression, and alcohol use among adolescents: a review of empirical findings. Int J Adolesc Med Health. 2007;19(1):27-35.

\section{Submit your next manuscript to BioMed Central and we will help you at every step:}

- We accept pre-submission inquiries

- Our selector tool helps you to find the most relevant journal

- We provide round the clock customer support

- Convenient online submission

- Thorough peer review

- Inclusion in PubMed and all major indexing services

- Maximum visibility for your research

Submit your manuscript at www.biomedcentral.com/submit 